\title{
Contrato organizativo da Ação Pública da saúde: instrumento de gestão administrativa em prol da responsabilidade sanitária
}

Organisational contract of Public Health Action: administrative management instrument for Health responsibility

\section{Paloma Pereira Almeida de Castro Santos ${ }^{1}$}

Resumo: A Reforma Sanitária Brasileira (RSB), consagrada como movimento de setores da sociedade, revela sua participação na elaboração do texto constitucional, que visou estabelecer a saúde como direito social. Posteriormente a esse processo, de forma contínua e concomitante, pode-se perceber que a RSB contribuiu com debates que culminaram na elaboração de leis que versam, em sua maioria, sobre a descentralização do SUS, enfatizando os instrumentos de gestão e promoção da saúde na União, nos Estados, no Distrito Federal e nos Municípios. Nesse contexto, surge como um elemento do Sistema Único de Saúde (SUS), o Contrato Organizativo da Ação Pública da Saúde (COAP), cujo objetivo é unificar e integrar as ações dos entes federativos, subsidiárias e complementares, levando em consideração as necessidades da região de saúde, dando ênfase à responsabilização dos gestores da saúde. Num panorama de fortalecimento da gestão da saúde, a responsabilidade sanitária, observada especialmente no COAP e no Projeto de Lei do Senado no 174/2011, para alguns estudiosos, como expletiva, vistas a regulamentação vigente acerca da responsabilidade civil atribuída à atividade estatal e a repartição de competências dentre os entes federativos e por outros, é concebida como importante instituto em prol de maior efetividade na prestação da saúde, carecendo de especificidade na tipificação. O presente artigo explicita, acerca da responsabilidade sanitária, questões a serem consideradas em ambos os institutos (COAP e PLS) e indica que, em termos evolutivos, há muito a se caminhar, porém, é indiscutível o desenvolvimento social já alcançado, no tocante à gestão compartilhada na saúde brasileira.

Palavras-chave: Responsabilidade Sanitária; Contrato Organizativo de Ação Pública; Gestão; Saúde pública e SUS

Abstract: The Brazilian Sanitary Reform (RSB), consecrated as a movement of sectors of society, can be clearly seen in its collaboration in the drafting of the constitutional text, which aimed to establish health as a social right. Subsequent to this process, continuously and concurrently, one can see that the RSB also contributed to debates that culminated in the drafting of laws that focused mostly on the decentralization of SUS, emphasizing management tools and health promotion in the Union, the states, the Federal District and the municipalities. In this context, as an element of the Unified Health System (SUS), the Organizational Agreement from the Public Health Action (COAP) arises, aiming to unify and integrate the actions of the federal entities, in a subsidiary and complementary manner, taking into consideration the needs of the health region, emphasizing accountability of managers. In a context of strengthening health management, the sanitary responsibility, together with COAP and Senate Bill $n^{\circ} 1,742,011$, can both be seen as unnecessary by

\footnotetext{
${ }^{1}$ Especialista em Estado e Sociedade Civil: Política e Gestão de ONG'S pela Faculdade de Ciência Política da Universidade de Brasília; em Direito Público pela Faculdade Fortium - DF; em Direito Sanitário pela Fundação Oswaldo Cruz em Brasília. Atua como Analista Processual na Secretaria de Regulação e Supervisão da Educação Superior/Ministério da Educação. E-mail: palomalmeida@hotmail.com
} 
some scholars, considering the current regulations on the liability attributed to the state activity and the division of powers among the federal entities. For others, it is conceived as an important institution for the sake of greater effectiveness in the provision of health, and lack specificity in typification. This article explains about the sanitary responsibility, questions to be considered in both institutes (COAP and PLS) and indicates that, in evolutionary terms, there is much to work; however, it is undeniable the social development already achieved with regard to shared management in health.

Keywords: Health Responsibility; Organizational Contract for Public Action; Management; Public health and SUS.

Resumen: La Reforma Sanitaria del Brasil, establecido como un movimiento con la participación de diversos sectores de la sociedad, reveló en su participación en la elaboración del texto constitucional, que tiene por objeto establecer la salud como un derecho social. Con posterioridad a este proceso, de forma continua y simultánea, se puede ver que la RSB también contribuyeron a los debates que culminaron en la elaboración de leyes que tienen que ver, sobre todo acerca de la necesaria descentralización del SUS, haciendo hincapié en herramientas de gestión y promoción de la salud en la Unión, los estados, el Distrito Federal y los municipios. En este contexto, surge el Acuerdo Organizacional de la Acción en Salud Pública, con el objetivo de unificar e integrar las acciones de todas las entidades federales, filial y de manera complementaria, teniendo en cuenta las necesidades de cada región del país. Por lo tanto, la responsabilidad sanitaria, como instituto específico para el fortalecimiento de la gestión de la salud, junto con el COAP, puede ser visto como innecesaria por algunos estudiosos, teniendo en cuenta las normas vigentes sobre la responsabilidad atribuida a la actividad del Estado y la división de poderes entre las entidades federales. Para otros, se concibe como una institución importante en aras de una mayor eficacia en la prestación de salud. En términos evolutivos, se entiende que aún hay mucho por conquistar; sin embargo, es innegable que parte del desarrollo social se ha logrado con respecto a la gestión compartida en la salud brasileña.

Palabras-Ilave: La responsabilidad de la salud; El contrato de organización de la acción pública; La gestión; La salud pública y el SUS

\section{Introdução}

A Reforma Sanitária Brasileira (RSB) constituiu-se em ampla mobilização de diversos setores da sociedade, podendo ser considerada como efetiva ação social, balizada pelo processo de redemocratização do país, na década de 1980 . O denominado „Movimento da Reforma Sanitária" (ANDRADE, et al, 2000) contou com a participação de múltiplos atores políticos, efetivando o arcabouço constitucional sanitário moderno, como configurado atualmente. 
Dessa forma, a disposição sanitária constitucional reveste-se de relevante avanço social, sendo apontada pela doutrina como dupla vertente em sua concepção, tendo em vista a natureza negativa em que o Estado e o particular devem abster-se da prática de atos que tragam riscos a terceiros e, de natureza positiva, referente à visão de fomento por parte do poder público na prestação e real implementação desse importante direito social (LENZA, 2014).

Ressalte-se de que é no prisma da prestação positiva do Estado na implementação do direito fundamental à saúde - que são conduzidas as discussões acerca do desafio de se concretizar o direito à saúde constitucionalmente consagrado, abandonando o caráter meramente retórico do texto legal (LENZA, 2014).

Com o objetivo de consolidar os elementos estruturantes para a implementação do Sistema Único de Saúde (SUS), a Carta Magna vigente traz em seu bojo dispositivos preliminares de direcionamento como o instituto da almejada descentralização, com uma rede regionalizada e hierarquizada (ANDRADE, et al, 2000).

Nesse ínterim, surgem institutos e fontes elementares, como um dos objetos de análise deste artigo, o Contrato Organizativo da Ação Pública da Saúde (COAP). Tal elemento tem como enfoque, a demonstração em instrumento escrito das ações e os serviços em saúde, disponíveis à população de determinado território e sua organização, dada de forma cooperativa e que visa conferir mais efetividade ao SUS, ampliando seu alcance democrático.

Da mesma forma, buscou-se a análise do PLS 174/2011, que ao definir e tipificar a denominada responsabilidade sanitária, contempla o COAP como seu principal elemento. Para tanto, o estudo que antecedeu a produção deste artigo. Assim, o seu desenvolvimento analítico, pautou-se em conteúdo descritivo, de fomento bibliográfico e documental, considerando desde a legislação constitucional existente até o arcabouço normativo infraconstitucional do COAP, refletindo em exame acerca da responsabilidade sanitária, confrontando os itens já existentes nas normativas analisadas com a enunciação legislativa proposta, exclusivamente, no Senado Federal. Em resumo, o objetivo do artigo é apresentar uma análise da responsabilidade sanitária presente no COAP e no PLS $174 / 2011$. 


\section{Reforma Sanitária e a Constituição Federal: a gestão geo compartilhada na saúde brasileira}

A VIII Conferência Nacional de Saúde, realizada em março de 1986, aglutinou setores organizados da sociedade, em prol do consenso de que a saúde no Brasil estivesse ao alcance de todos. Assim, teria de possuir não somente uma reforma contemplando as áreas administrativa e financeira, mas, também, deveria configurar-se como uma efetiva alteração de todo o arcabouço jurídico-institucional vigente, no qual contemplasse o ideal de saúde, conforme o disposto no cerne da reforma sanitária. Portanto, o relatório produzido, nesse evento, tornou-se o marco referencial para os constituintes da Lei Maior de 1988 (ANDRADE, et al, 2000).

Oriundo do processo democrático, o denominado movimento sanitário tinha realizações definidas para consolidar como principalmente, a saúde como direito de todo o cidadão, independente de contribuição. Assim, não se poderia excluir ou segregar qualquer cidadão brasileiro do acesso à assistência pública de saúde. Havia também o olhar secundário, de que as ações de saúde devessem garantir o acesso da população às ações de âmbito preventivo e/ou curativo e, com isso, teriam que, necessariamente, estar adicionadas em um único sistema. De forma terciária, previu a descentralização da gestão (administrativa e financeira), até para possibilitar o controle social das ações de saúde, este como elemento quaternário (MINISTÉRIO DA SAÚDE, 2014).

Embasado nos ideais indicados, o direito à saúde foi elevado, por conseguinte, à condição de direito fundamental, expressamente prevista na Carta Cidadã Brasileira. Não se pode cogitar que, um direito de relevância inquestionável para a implementação de uma sociedade pautada na promoção de melhores condições de vida dos cidadãos, visando à igualdade de oportunidades e tratamento condigno, não figure nas normas constitucionais de proteção aos direitos fundamentais (SILVA, 2005).

Obstinada e determinada como a RSB, a Lex Matter surgiu inaugurando uma democrática visão sanitária brasileira, objetivando sistematizar, bem como garantir as ações e serviços destinados à promoção, proteção, preservação e recuperação da saúde do indivíduo e da coletividade, de forma a garantir: a) saúde como um direito do cidadão e dever estatal; b) ações e serviços de saúde, como elementos de relevância pública; c) cobertura e atendimento universal, para equidade da assistência; d) gestão administrativa descentralizada, somada à participação comunitária garantida; e) rede pública de serviços 
integrada em um sistema único; f) probabilidade participativa do setor privado de serviços no sistema público de saúde, de forma complementar; g) financiamento pelos orçamentos da União, Estados e Municípios; h) direção única nas esferas das entidades federativas; e i) consequência de condicionantes que definem a circunstância de bem-estar físico, mental e social do indivíduo e de políticas sociais econômicas aplicadas (ANDRADE, et al, 2000).

Dessa forma, o direito à saúde está previsto na Constituição Brasileira, alocada dentre os direitos sociais, conforme declaração expressa contida no art. $6^{\circ}$, prevendo, ainda, o art. 196 da mesma Carta Legal (BRASIL, 1988), „a saúde é direito de todos e dever do Estado, garantido mediante políticas sociais e econômicas que visem à redução do risco de doença e de serviços para sua promoção, proteção e recuperação".

Tal status de norma constitucional, especialmente relacionada aos direitos fundamentais, impõe ao Estado, de forma direta e imediata, a implementação da saúde de forma eficaz, por meio de políticas públicas abrangentes (ALVES et al, 2013).

Com referência à competência comum entre a União, os Estados, o Distrito Federal e os Municípios, o art. 23 do mesmo Compêndio Constitucional conduz a todos os entes citados a responsabilidade no cuidado com a saúde, para proteção e exercício da integralidade.

O art. 197 da Constituição Federal define que são de relevância pública as ações e serviços de saúde, sendo de responsabilidade do Poder Público determinar, com observância da lei, sobre sua regulamentação, fiscalização e controle, com execução a ser realizada de forma direta ou por intermédio de terceiros e, ainda, por pessoa física ou jurídica de direito privado.

Nos termos do art. 198 da Carta Política (BRASIL, 1988), ressalta-se que as ações e serviços de saúde agregam uma rede regionalizada e hierarquizada e formam um sistema único, organizado conforme as diretrizes de descentralização, atendimento integral e com participação da comunidade. O conjunto de instituições responsáveis pela execução de ações e serviços públicos de saúde compõe o Sistema Único de Saúde (SUS). 


\section{O Contrato Organizativo de Ação Pública como instrumento de gestão compartilhada}

Após a promulgação do Magno Texto Republicano de 1988, fez-se eminente a criação do SUS. Coube ao Congresso Nacional a importante missão de regulamentar os dispositivos constitucionais relacionados ao âmbito da saúde, nos termos das Leis $8.080 / 1990$,e $8.142 / 1990$,as quais dispuseram sobre as condições para a promoção, proteção e recuperação da saúde, a organização e o funcionamento dos serviços em saúde, bem como a participação social na gestão do SUS e referentes transferências de recursos entre os entes governamentais (BRASIL, 2011).

Na Lei Orgânica da Saúde, Lei no 8.080/1990 (BRASIL, 1990), em seus arts. 16 a 19, há a disposição descritiva das competências em âmbito nacional, estadual, distrital e municipal, com o enfoque de abranger a integralidade de todas as ações e serviços em saúde.

Contudo, mesmo com o marco legislativo infraconstitucional que fundou as especificidades do SUS, com enfoque nas diretrizes de universalidade e integralidade, dentre outros, verificou-se lacunas alusivas ao planejamento, organização e articulação entre os diversos atores envolvidos na prestação da saúde (BRASIL, 2011).

Cumpre ressaltar que, no decorrer últimos dos anos, a Lei 8.080/1990 (BRASIL, 1990) sofreu algumas alterações com intuito de aprimorar os mecanismos e instrumentos de prestação da saúde no âmbito do SUS.

Em 2011, foi editado pelo Poder Executivo o Decreto ํo 7.508/2011 (BRASIL, 2011a), regulamentando a Lei Orgânica da Saúde, dispondo sobre o planejamento da saúde, a assistência à saúde e a articulação interfederativa.

O Decreto 7.508/2011 (BRASIL, 2011a), previu, com vistas a conceder maior transparência e delineamento das ações na gestão do SUS, o Contrato Organizativo de Ação Pública (COAP), instrumento pautado na identificação das responsabilidades assumidas pelos entes federados envolvidos na prestação da saúde, em determinado território, conforme disposições constitucionais e infralegais definidas (BRASIL, 2011).

Nesse sentido, o Decreto no 7.508 (BRASIL, 2011a) apresenta em seu art. 2º, inciso II, o conceito para o COAP, definido como "acordo firmado entre os entes federativos com a finalidade de organizar e integrar as ações e serviços em saúde, dispondo detalhadamente da área de atuação em saúde". Como ferramenta de transparência e 
realidade social das ações e serviços de saúde, dentro do COAP, em seu Anexo II, está a Programação Geral das Ações e Serviços de Saúde (PGASS), a qual se constitui como fundamento para compor os meios de regulação, controle, avaliação e até auditoria, com relação à observância dos objetivos quantitativos e qualitativos acordados.

Com esse entendimento, Santos (2012) salienta a importância dos compromissos ratificados pelo COAP:

É importante esclarecer que o contrato tem finalidades mais abrangentes que as transferências interfederativas por seu objeto ser a "organização e a integração das ações e dos serviços de saúde, sob responsabilidade dos entes federativos em uma região de saúde, com a finalidade de garantir a integralidade da assistência aos usuários" (art. 34 do Decreto n $n^{\mathrm{a}}$ 7.508).

Esse novo modelo buscou dirimir a indefinição acerca de qual esfera governamental é a responsável por assegurar os serviços de saúde que necessitam de maior investimento tecnológico e, ainda garantir o financiamento adequado para as regiões envolvidas, sendo essas as demandas que sempre geraram preocupação entre os gestores. (SHIMIZU, 2013).

O espaço aberto à negociação interfederativa é realizado essencialmente pelo processo de elaboração do contrato, oferecendo aos entes a definição, conforme suas características, responsabilidades individuais e solidárias, com a negociação respaldada nas necessidades de saúde da região, com a assunção de serviços efetivos para a saúde da população (SANTOS, 2013).

O diploma legal elencado (BRASIL, 2011), discrimina em seu Capítulo V - Da Articulação Interfederativa, Seção II - Do Contrato Organizativo da Ação Pública da Saúde, artigos 33 a 41, de forma objetiva e concisa sobre como deve ser e que pontos devem conter a apresentação do COAP. Os itens pretendem acurar requisitos considerados pela norma, indispensáveis à assunção de responsabilidades e colaboração entre os entes federativos, com o objetivo de organizar a rede de atenção à saúde, com foco na assistência aos usuários de forma integral às ações e serviços em saúde.

Para o deslinde do instrumento em debate, importe é a acepção elucidativa de Dobashi (2014):

É necessária, sem dúvida, uma ação mais efetiva do Ministério da Saúde, bem como a realização de debates tripartites que analisem a situação e desenhem estratégias de continuidade, já que o COAP não pretende ser apenas um instrumento formal de ação conjunta, mas sim o retrato das intervenções regionais destinadas a buscar a integralidade da atenção em saúde através da atuação em rede. 


\section{Responsabilidade Sanitária: os desafios de implementação na gestão compartilhada}

A atividade administrativa do Estado, também entendida, atualmente, em sentido amplo, como o exercício da Administração Pública por meio de atos de ordenação, prestação e fomento mediante instrumentos de convênio ou contratos celebrados pelo poder estatal (FURTADO, 2013), está sujeita aos princípios balizadores do Estado Democrático de Direito, submetendo-se, inclusive, aos órgãos de controle para 0 cumprimento do interesse público esculpido na Carta Magna.

O dinamismo da sociedade acarreta em novas formas de atuação estatal e, consequentemente, em novos desafios na busca de instrumentos hábeis a regular as relações entre Estado o e a sociedade. Nesse sentido, busca-se uma maior presteza na atualização dos preceitos legais integrantes da atividade administrativa do Estado, visando ao atendimento dos anseios sociais, sem o afastamento dos regramentos jurídicos que alicerçam o Estado Democrático de Direito (FURTADO, 2013).

O aprimoramento das políticas públicas demanda por instrumentos fortalecidos e que reflitam uma escorreita aplicação de recursos na consecução dos fins almejados pelo Estado. Assim, há de se crer, que tanto os instrumentos que antecederam o COAP, como o próprio, primam por fortalecer a gestão integrada entre os entes, a adequada aplicação de recursos públicos e todos os ideais abarcados pela Carta Maior.

Acerca dos mecanismos e instrumentos de controle concebidos no decorrer da implementação do SUS, Romero e Delduque (2013) afirmam que eles caminham no sentido de desenvolver o regramento da cooperação intergovernamental, para homenagear a articulação entre os entes federativos, carecendo, no entanto, tais regramentos, de mecanismos de controle e responsabilização entre os entes envolvidos.

Ainda que existam normas, penalidades como as da Lei no 8.429, de 2 de junho de 1992 (BRASIL, 1992) e da Lei Complementar no 141, de 13 de janeiro de 2012 (BRASIL, 2012); bem como, os normativos responsáveis pela execução de controles que submetem o SUS, à exemplo dos controles internos (Sistema Nacional de Auditoria do SUS, previsto no Decreto no 1651, de 28 de setembro de 1995 (BRASIL, 1995) e atuação da Controladoria Geral da União prevista na Lei no 10.683, de 28 de maio de 2003) e externos, como a atuação do Tribunal de Contas da União e entes sociais (Conselhos e Conferências de saúde, conforme prevê a Lei no 8142/90), a inexistência de lei específica acerca da responsabilidade sanitária têm promovido o intento de inovar legislativamente, 
de modo a contemplar respostas para as irregularidades apuradas em desfavor dos responsáveis pela gestão em saúde.

A responsabilização decorrente da atividade estatal, nos termos dos ensinamentos de Di Pietro (2013) envolve as esferas civil, penal e administrativa, em razão de atos decorrentes do exercício do cargo, função ou emprego.

Acerca da responsabilidade civil, leciona Furtado (2013):

A responsabilidade civil do servidor está vinculada ao dever de ressarcir prejuízos causados à Administração Pública ou a terceiros em decorrência de ato omissivo ou comissivo, doloso ou culposo, provocados em decorrência do exercício de suas atribuições.

No tocante à responsabilidade penal, haverá responsabilização quando for constatada uma ação ou omissão, antijurídica, causando dano ou perigo de dano ao bem jurídico tutelado no tipo incriminador (DI PIETRO, 2013).

A responsabilidade administrativa, por sua vez, determina que o agente público responde pelos seus atos, de acordo com o definido na legislação administrativa, possuindo os mesmos elementos do ilícito civil (DI PIETRO, 2013).

Surge, nesse sentido, a necessidade de se aprimorar as discussões em relação ao instituto da Responsabilidade Sanitária, para que compreenda a especificidade advinda de eventual alteração dos institutos jurídicos próprios relacionados ao âmbito da saúde.

É indispensável ressaltar que proposições legislativas atuais vêm adotando um conceito amplo acerca dos atores envolvidos na gestão do SUS, abrangendo assim todos os responsáveis pela gestão e realização de algum serviço público, sendo este de caráter transitório ou permanente (ROMERO; DELDUQUE, 2013).

Com o mesmo entendimento caminham as mais hodiernas propostas de implementação de um regramento jurídico próprio em relação à responsabilização dos gestores de saúde, mudando-se o foco de responsabilização do ente público para o gestor do SUS (ROMERO; DELDUQUE, 2013).

Cita-se, nesse diapasão, dois importantes Projetos de Lei (PL) que versam sobre a adoção de procedimentos de implementação da responsabilidade sanitária aos gestores do SUS. Em pesquisa legislativa, exclusivamente no âmbito do Senado Federal, cumpre mencionar que o Projeto de Lei do Senado (PLS) no 190/2009 (BRASIL, 2009) dirigiu-se com o fulcro de alterar a Lei no 8080/1990 (BRASIL, 1990), para definir procedimentos a 
serem adotados na apuração de responsabilidades e estabelecer sanções a serem aplicadas aos agentes públicos responsáveis pelo descumprimento injustificado de obrigações assumidas no âmbito do SUS. Indica ainda, que o PLS no 174/2011 (BRASIL, 2011), cujo escopo é a alteração do mesmo diploma legal, com vistas a instituir regras referentes à elaboração de planos de saúde e inserir dispositivos que regulam a responsabilidade sanitária dos gestores no âmbito do SUS.

Os aludidos PLS, após aprovação de requerimento, tramitaram em conjunto, no Senado Federal, até 07 de maio de 2014, oportunidade em que, com a apreciação desses documentos na Comissão de Assuntos Sociais (CAS) daquela Casa, foram aprovadas, por decisão terminativa, as proposições e emendas incluídas no PL no 174/2011 (BRASIL, 2011), configurando como rejeitado o PL ํㅜ190/2009 (BRASIL, 2009), juntamente com as suas emendas de bojo.

Cabe informar que o PLS no 174/2011 (BRASIL, 2011), em dezembro de 2014, ocasião em que se deu este estudo, encontrava-se em tramitação na Câmara dos Deputados, e tratava da tipificação de determinados atos praticados pelos gestores, consubstanciados em ilícitos de maior gravidade, como crimes de responsabilidade sanitária, podendo levar à comparação com os crimes de responsabilidade regulados pela Lei no 1.079/50 (ROMERO; DELDUQUE, 2013) e pelo Decreto-Lei nํ 201/67, que versa sobre a responsabilidade de prefeitos e vereadores.

Para os defensores de tal proposta legislativa, a ampliação da responsabilidade da esfera administrativa, para esfera criminal, representa um maior poder dissuasório para eventuais descumprimentos de contratos e metas estipuladas entre os gestores envolvidos (ROMERO; DELDUQUE, 2013). Vale acentuar, por oportuno, que a proposição legislativa (BRASIL, 2011) considera como „gestores solidários do Sistema Único de Saúde os chefes do Poder Executivo da União, dos Estados, do Distrito Federal e dos Municípios, bem como os titulares dos respectivos órgãos do Sistema".

Outro item trazido pelo PL no 174/2011 (BRASIL, 2011) trata das previsões de medidas saneadoras, não punitivas com o fito de aprimoramento das rotinas de gestão, por intermédio dos Termos de Ajuste de Conduta Sanitária (TACS). Possibilidade esta excluída, nos casos de dano ao erário (desfalque ou desvio de dinheiro, bens ou valores públicos). Romero e Delduque (2013) entendem que a proposta referenciada tem como premissa equacionar um viés de ineficiência existente no processo formal atual, 
estabelecendo o controle da responsabilidade sanitária, resultando no enfoque para implementação de mecanismos mais eficientes na gestão do sistema (ROMERO; DELDUQUE, 2013).

O PLS no 174/2011 (BRASIL, 2011), também apresenta itens relacionados ao pacto de gestão, existente no SUS, entre os entes federados. Refere-se ao acréscimo na Lei 8.080/1990 (BRASIL, 1990), do artigo 38-D, dispositivo com o fulcro de estabelecer as formas de cooperação intergestores, e determinar o cumprimento das obrigações das responsabilidades relativas à oferta de ações e serviços de saúde, meio de compromissos assumidos em pactos federativos firmados através dos COAP.

Destaca-se, que tais pactos, com o advento de sua celebração, transformar-se-ão, nos termos da proposta legislativa em atenção (BRASIL, 2011), como instrumentos de valor jurídico, basilando-se como líquidas e certas as obrigações assumidas pelos partícipes, com eficácia de título executivo extrajudicial.

Contudo, há que explicitar alguns debates oriundos da presente análise do PLS 174/2011 (BRASIL, 2011). Primeiramente, a proposição em comento antecede a aprovação da lei 12.466/2011 (BRASIL, 2011b) - que alterou a lei 8.080/90 - e a Lei Complementar 141/12 (LC 141/12), que regulamentou a Emenda Constitucional 29/2000, o que de pronto, influencia o teor proposto.

Outro item importante refere ao Artigo 36 do referido PLS (BRASIL, 2011), que entende o COAP como instrumento determinante para os planos de saúde. Na prática tal relação se inverte, vez que os planos de saúde, de caráter plurianual, é que devem contemplar ações que serão discriminadas em programação anual e também nos COAP, conforme disposto pela PGASS.

Ao comparar a proposta legislativa com o disposto em legislação já vigente, parte do artigo 38-D, trazido pelo PLS 174/2011 (BRASIL, 2011), já foi legislada no Artigo 14-A e 14-B da lei 12.466/2011 (BRASIL, 2011b), inclusive com abordagem acerca dos Conselhos Representativos e sua atuação, restando-lhe o que refere ao COAP.

Da mesma forma, já há na LC 141/12 (BRASIL, 2012), em seu artigo 36 e §§, determinação acerca do instrumento de prestação de contas no SUS - o relatório de gestão, conferindo-Ihe formato diferente do disposto no Artigo 38-F da proposta legislativa analisada. 
A LC 141/12 (BRASIL, 2012) prevê em seus artigos 26 e 38, que cabe aos Tribunais de Contas a verificação do cumprimento da aplicação dos percentuais de receita na setorial saúde e não aos Conselhos de Saúde, conforme prevê o artigo 38-E da proposição em tela.

Há ainda no PLS 174/2011 (BRASIL, 2011), renumerado na Câmara dos Deputados para PLC 7585/2014 (BRASIL, 2014), discussões importantes e inadiáveis para a gestão do SUS, tais como:

1 - responsabilidade entre os entes federados com entendimentos diferentes. Hodiernamente o Supremo Tribunal Federal (STF) vem se posicionado favoravelmente ao entendimento pela solidariedade, todavia, há em curso debates acerca da responsabilização por competências (respeitadas às definições da lei 8.080/90) e conforme explicitado no Enunciado $8^{\circ}$ do Fórum de Saúde do Conselho Nacional de Justiça, que dispõe que „nas condenações judiciais sobre ações e serviços de saúde devem ser observadas, quando possível, as regras administrativas de repartição de competência entre os gestores".

2 - o descumprimento do artigo 31 da LC 141/12 (BRASIL, 2012), configurado na ferramenta eletrônica que tipifica modelos e parâmetros para a elaboração de planos de saúde, tornando padronizadas as realidades desiguais;

3 - a proposta de estruturação obrigatória de componente do Sistema Nacional de Auditoria (SNA), em todos os entes da federação, podendo ensejar despesa insuportável aos municípios de pequeno porte - já dotados de outros instrumentos de controle interno;

4 - debates sobre o subfinanciamento da política de saúde pública no Brasil, expresso no artigo 15 do Decreto 7.508/11 (BRASIL, 2011a) que indica a compatibilização das necessidades da política de saúde à disponibilidade de recursos financeiros e que não encontrou eco na proposição legislativa à assunção do COAP por instrumento de lei, visto que tal instrumento revela estratégia de gestão para o SUS, já representada no Decreto 7.508/11 (BRASIL, 2011a). Tal preocupação deriva-se da observação do histórico da política de saúde no país, que atravessou regras expressas nas Normas Operacionais Básicas (NOB 1991, NOB 1992, NOB 1993, NOB 1996) nas Normas Operacionais de Assistência à Saúde (NOAS 2000 / NOAS 2002), no Pacto pela Vida de 2006 e, finalmente, no COAP de 2011. Os instrumentos da gestão significaram, ao longo do tempo, 
a adequação do SUS à sua progressão e à sua prospecção e sua aposição em lei, a qual deve ser precedida de debates pelos gestores em saúde.

Tais itens foram apresentados, sem a intenção de posicionamento contrário ou favorável ao COAP ou ao comentado PLS. Todavia, pretende-se elucidar que não houve debates suficientes acerca de tudo o que compõem a Responsabilidade Sanitária derivada do COAP e representada na proposta legislativa.

\section{Considerações finais}

Pode-se dizer que os ideais da RSB continuaram contribuindo na regulamentação do texto constitucional, nas discussões que resultaram na promulgação de importantes leis infraconstitucionais, especialmente as que disciplinaram a descentralização políticoadministrativa do SUS, prevista constitucionalmente, e, ainda, enfatizaram os instrumentos de gestão e promoção da saúde, nas três esferas governamentais.

O avanço disposto pelas diretrizes constitucionais, consubstanciadas na criação de um sistema único, com articulação dos entes por meio de Conselhos Representativos e Comissões Intergestores, de visão construtiva, descentralizada e cooperativa, apresentou desafios aos gestores da saúde, porquanto as desigualdades e características inerentes a determinadas regiões, estas nem sempre demarcadas por limites territoriais, impuseram uma ação específica para o atendimento dessas peculiaridades, sob pena de se expandir, bem como intensificar, as disparidades existentes na sociedade brasileira.

Dando continuidade ao histórico dos instrumentos normativos aplicáveis à gestão do SUS, frutos da progressão da gestão, dos indicadores e maturação das discussões acerca das necessidades de cada localidade, emerge em substituição ao Pacto pela Vida, o COAP.

Esse instrumento de gestão administrativa, visto como pacto firmado entre os entes federados, com o desiderato de organizar e integrar as ações e serviços em saúde, por meio de negociação, pretende demonstrar as necessidades reais de saúde de determinada região, conferindo transparência às ações e serviços de saúde tangíveis à população. Os pactos firmados entre os entes federativos, com o propósito de se implementar e aperfeiçoar a política de saúde, devem primar pela efetividade na condução desses processos, com o desígnio macro de ultrapassar os obstáculos impostos pelos diversos 
interesses político-administrativos que possam vir a esvaziar e enfraquecer a melhor gestão da saúde no Brasil.

Neste desiderato é de reconhecer que tanto o COAP, quanto o PLS 174/2011 (PLC 7585/2014) representam discussões, respectivamente entre gestores do SUS, o Poder Legislativo, setores da sociedade, academia, no tocante à responsabilização dos gestores em saúde, como nos casos de configuração de má condução dos processos e aplicação dos recursos destinados à saúde de maneira distinta ao fim determinado, inclusive com a proposição de sanção àqueles pela lesão ao direito à saúde da população.

Há que se reconhecer o grande esforço no caminho de se efetivar, por intermédio de instrumentos próprios atinentes à práxis, doutrina e legislação brasileira, seja para integração dos vários atores envolvidos nas três esferas governamentais e nos poderes constituídos, seja para punir aqueles que não tenham honrado a gestão na saúde.

Todavia, conforme demonstrado neste estudo alguns debates ainda padecem de enfrentamento. Os desafios são de amplitude condizente com os avanços sociais implementados pela Constituição Cidadã e ainda há muito a ser feito, sob pena de que leis sejam vistas como letras mortas.

\section{Referências bibliográficas}

AlVES, S. M. C.; DELdUQUE, M. C.; DINO NETO, N. (Org.). Direito Sanitário em Perspectiva, Brasília: ESMPU, 2013. 333 p. Disponível em: http://escola.mpu.mp.br/linhaeditorial/outras-publicacoes/DireitoSanitarioEmPerspectiva.pdf. Acesso em: 25 set. 2014.

ANDRADE, L. O. M., PONTES, R. J. SOARES JUNIOR,T. M. A descentralização no marco da Reforma Sanitária no Brasil. Rev. Panam Salud Publica, Washington, vol.8, n.12, p. 8492, Jul./Aug. 2000.

http://www.scielosp.org/scielo.php?script=sci arttext\&pid=S1020-49892000000700026

Acesso em: 01 nov. 2014.

BRASIL. Câmara Federal. Projeto de Lei 7.585/2014, de 21 de maio de 2014. Altera a Lei no 8.080, de 19 de setembro de 1990, para inserir dispositivos que regulam a responsabilidade sanitária dos gestores no âmbito do Sistema Único de Saúde (SUS). Disponível em:

$<$ http://www.camara.gov.br/proposicoesWeb/fichadetramitacao?idProposicao=616324> Acesso em: 20 nov. 2014.

BRASIL. Constituição da República Federativa do Brasil (1988). Brasília: Senado Federal. Disponível em:

http://www.planalto.gov.br/ccivil 03/constituicao/constituicaocompilado.htm. Acesso em: 01 out. 2014. 
BRASIL. Presidência da República. Decreto oํ 1.651, de 28 de setembro de 1995. Regulamenta o Sistema Nacional de Auditoria no âmbito do Sistema Único de Saúde. Diário Oficial da União, Brasília, DF, 29 set. 1995. Disponível em: http://www.planalto.gov.br/ccivil 03/decreto/1995/d1651.htm. Acesso em: 20 nov. 2014.

BRASIL. Presidência da República. Decreto no 7.508, de 28 de junho de 2011 a. Regulamenta a Lei $\mathrm{n}$-8.080, de 19 de setembro de 1990, para dispor sobre a organização do Sistema Único de Saúde-SUS, o planejamento da saúde, a assistência à saúde e a articulação interfederativa, e dá outras providências. Diário Oficial da União, Brasília, DF, 29 jun. 2011. Disponível em: http://www.planalto.gov.br/ccivil 03/ ato20112014/2011/decreto/D7508.htm. Acesso em: 01 out. 2014.

BRASIL. Presidência da República. Decreto-Lei no 201, de 27 de fevereiro de 1967. Dispõe sobre a responsabilidade dos Prefeitos e Vereadores, e dá outras providências. Diário Oficial da União, Brasília, DF, 27 fev. 1967. Disponível em: http://www.planalto.gov.br/ccivil 03/decreto-lei/del0201.htm. Acesso em: 18 out. 2014.

BRASIL. Presidência da República. Lei Complementar nํ 141, de 13 de janeiro de 2012. Regulamenta $\circ \S 3^{30}$ do art. 198 da Constituição Federal para dispor sobre os valores mínimos a serem aplicados anualmente pela União, Estados, Distrito Federal e Municípios em ações e serviços públicos de saúde; estabelece os critérios de rateio dos recursos de transferências para a saúde e as normas de fiscalização, avaliação e controle das despesas com saúde nas 3 (três) esferas de governo; revoga dispositivos das Leis $\mathrm{n}$ os 8.080 , de 19 de setembro de 1990, e 8.689, de 27 de julho de 1993; e dá outras providências. Diário Oficial da União, Brasília, DF, 16 jan. 2012. Disponível em: http://www.planalto.gov.br/ccivil 03/leis/lcp/Lcp141.htm. Acesso em: 20 nov. 2014.

BRASIL. Presidência da República. Lei no 1.079, de 10 de abril de 1950. Define os crimes de responsabilidade e regula o respectivo processo de julgamento. Diário Oficial da União, Brasília, DF, 12 abr. 1950. Disponível em: http://www.planalto.gov.br/ccivil 03/leis/l1079.htm. Acesso em: 18 out. 2014.

BRASIL. Presidência da República. Lei no 10.683, de 28 de maio de 2003. Dispõe sobre a organização da Presidência da República e dos Ministérios, e dá outras providências.

Diário Oficial da União, Brasília, DF, 29 mai. 2003. Disponível em: http://www.planalto.gov.br/ccivil 03/leis/2003/l10.683.htm. Acesso em: 20 nov. 2014.

BRASIL. Presidência da República. Lei no 12.466, de 24 de agosto de 2011b. Acrescenta arts. 14-A e 14-B à Lei $\mathrm{n}$ - -8.080 , de 19 de setembro de 1990, que dispõe sobre as condições para a promoção, proteção e recuperação da saúde, a organização e o funcionamento dos serviços correspondentes e dá outras providências, para dispor sobre as comissões intergestores do Sistema Único de Saúde (SUS), o Conselho Nacional de Secretários de Saúde (Conass), o Conselho Nacional de Secretarias Municipais de Saúde (Conasems) e suas respectivas composições, e dar outras providências. Diário Oficial da União, Brasília, DF, 25 ago. 2011. Disponível em: http://www.planalto.gov.br/ccivil 03/ Ato2011-2014/2011/Lei/L12466.htm. Acesso em: 20 nov. 2014]. 
BRASIL. Presidência da República. Lei no 8.080 , de 19 de setembro de 1990. Dispõe sobre as condições para a promoção, proteção e recuperação da saúde, a organização e o funcionamento dos serviços correspondentes e dá outras providências. Diário Oficial da União, Brasília, DF, 20 set. $1990 . \quad$ Disponível em: http://www.planalto.gov.br/ccivil 03/leis/l8080.htm. Acesso em: 15 out. 2014].

BRASIL. Presidência da República. Lei o 8.142, de 28 de dezembro de 1990a. Dispõe sobre a participação da comunidade na gestão do Sistema Único de Saúde (SUS\} e sobre as transferências intergovernamentais de recursos financeiros na área da saúde e dá outras providências. Diário Oficial da União, Brasília, DF, 31 dez. 1990. Disponível em: http://www.planalto.gov.br/ccivil 03/leis/l8142.htm. Acesso em: 15 out. 2014.

BRASIL. Senado Federal. Projeto de Lei do Senado 174/2011, de 19 de abril de 2011. Altera a Lei no 8.080, de 19 de setembro de 1990, para modificar o art. 36, que institui regras sobre a elaboração dos planos de saúde, e para inserir dispositivos que regulam a responsabilidade sanitária dos gestores no âmbito do Sistema Único de Saúde.. Disponível em: http://www.senado.gov.br/atividade/materia/detalhes.asp?p cod mate=99951. Acesso em: 10 out. 2014

BRASIL. Senado Federal. Projeto de Lei do Senado 190/2009, de 12 de maio de 2009. Altera a Lei $n^{\circ} 8.080$, de 19 de setembro de 1990, para definir procedimentos a serem adotados na apuração de responsabilidades e estabelecer sanções a serem aplicadas aos agentes públicos responsáveis pelo descumprimento injustificado de obrigações assumidas no âmbito do Sistema Único de Saúde. Disponível em: < http://www.senado.gov.br/atividade/materia/detalhes.asp?p cod mate=91004>. Acesso em: 10 out. 2014.

DI PIETRO, M.S.Z. Direito Administrativo. São Paulo: Editora Atlas, 2014. 966 p.

DOBASHI, B. F. Os Caminhos da Gestão em Saúde no Mato Grosso do Sul: da reforma sanitária ao COAP. Campo Grande: MS, 2014. 92 p.

FURTADO, L. R. Curso de Direito Administrativo. Belo Horizonte: Editora Fórum, 2013. $1013 \mathrm{p}$.

LENZA, P. Direito Constitucional Esquematizado. São Paulo: Saraiva, 2014. 1452 p. MINISTÉRIO DA SAÚDE. Escola Nacional de Saúde Pública Sérgio Arouca (ENSP), Assistência Farmacêutica à luz da proposta da Reforma Sanitária Brasileira. Rio de Janeiro, 2014. Disponível em: http://www.ensp.fiocruz.br/portalensp/judicializacao/pdfs/introducao.pdf. Acesso em: 08 out 2014.

MINISTÉRIO DA SAÚDE. Secretaria de Gestão Estratégica e Participativa. Regulamentação da Lei no 8.080 para fortalecimento do Sistema Único da Saúde: decreto 7508, de 2011. Rev Saúde Pública, São Paulo, v.45, n.6, p.1206-7, 2011. Disponível em: http://www.scielo.br/scielo.php?pid=S0034-89102011000600025\&script=sci arttext.

Acesso em: 25 out. 2014. 
ROMERO, L.C.P, DELDUQUE, M.C. A instituição da responsabilidade sanitária pela via legal no Brasil. Saúde soc, São Paulo, v.22, n.4, p. 1167-1179, 2013. Disponível em: http://www.scielo.br/scielo.php?pid=S0104-12902013000400018\&script=sci arttext. Acesso em: 05 nov. 2014.

SANTOS, Lenir. Contrato Organizativo de Ação Pública (COAP). Blog Direito Sanitário: Saúde e Cidadania dez. 2013. Disponível em http://blogs.bvsalud.org/ds/2013/12/27/contrato-organizativo-de-acao-publica-coap/. Acesso em: 05 out. 2014.

SANTOS, L. SUS e a Lei Complementar 141 Comentada. Campinas: Saberes Editora, 2012. $221 \mathrm{p}$.

SHIMIZU, H. E. Percepção dos Gestores do Sistema Único de Saúde acerca dos Desafios da Formação das Redes de Atenção à Saúde no Brasil. Physis: Revista de Saúde Coletiva, Rio de Janeiro, v.23, n. 4, p. 1101-1122, 2013. Disponível em: http://scielo.br/scielo.php?pid=S0103-73312013000400005\&script=sci arttext\&ting=es. Acesso em: 15 out. 2014.

SILVA, J. A. da. Curso de Direito Constitucional Positivo. São Paulo: Malheiros, 2005. 924 p. 